\title{
Can the positions of the spastic upper limb in stroke survivors help muscle choice for botulinum toxin injections?
}

\author{
A posição do membro superior de indivíduos com doença cerebrovascular pode auxiliar na \\ escolha de músculos para a injeção de toxina botulínica?
}

André Luiz Salcedo GOMES', Francisco Falleiros de MELLO', Jorge COCICOV NETO', Marcelo Causin BENEDETI', Luis Felipe Miras MODOLO', Marcelo RIBERTO'

\begin{abstract}
Motor impairments in stroke survivors are prevalent and contribute to dependence in daily activities, pain and overall disability, which can further upper-limb disability. Treatment with botulinum toxin A (BoNT-A) is indicated for focal spasticity and requires knowledge of biomechanics and anatomy to best select muscles to be injected in the limb. Objective: We aimed to describe the frequency of posture patterns in a Brazilian sample of stroke survivors and correlate them with recommendations of muscle selection for treatment with BoNT-A. Methods: Fifty stroke patients with spastic upper limbs scheduled for neuromuscular block were photographed and physically examined, to be classified by three independent evaluators according to Hefter's classification. Muscles that were injected with BoNT-A by their routine doctors were retrieved from medical charts. Results: Pattern III and IV were the most common (64.7\%, 21.6\%). We further subclassified pattern III according to the rotation of the shoulder, which effectively interfered in muscle choice. The muscles most frequently treated were shoulder adductors and internal rotators, elbow flexors and extensors, in forearm, the pronator teres and finger and wrist flexors, and, in the hand the adductor pollicis. Conclusion: Frequencies of upper-limb postures differed from previous reports. Other clinical features, besides spasticity, interfered with muscle choice for BoNT-A injection, which only partially followed the recommendations in the literature.
\end{abstract}

Keywords: Cerebrovascular disorders; muscle spasticity; botulinum toxins, type A; rehabilitation; goals.

\section{RESUMO}

As deficiências motoras que ocorrem nos indivíduos com doença cerebrovascular (DCV) são prevalentes e contribuem para dependência, dor e incapacidade, o que pode atrasar a reabilitação do membro superior e sua funcionalidade. 0 tratamento com toxina botulínica do tipo A (BoNT-A) é indicado para a espasticidade focal e requer conhecimento da biomecânica e anatomia para melhor selecionar os músculos a serem injetados. Objetivo: Descrever a frequência de padrões posturais numa amostra de brasileiros com sequelas de DCV e correlacioná-los com as recomendações de seleção de músculos. Métodos: Cinquenta pacientes com comprometimento do membro superior devido a DCV do ambulatório de bloqueios neuromusculares foram fotografados e examinados para categorização de acordo com a Classificação de Hefter. Os músculos tratados pelos seus médicos de rotina foram obtidos a partir dos prontuários. Resultados: Os padrões III e IV de Hefter foram mais comuns (64,7\%; 21,6\%). Nós propusemos a subclassificação do padrão III de acordo com a rotação do ombro, pois isso interferiu na escolha dos músculos tratados. Os músculos tratados com maior frequência foram os adutores e rotadores internos do ombro; flexores e extensores do cotovelo; no antebraço, o pronador redondo, flexores dos dedos e do carpo e na mão, o adutor do polegar. Conclusão: As frequências das posições do membro superior diferiram de relatos prévios. Além da espasticidade, outros fatores interferiram na escolha dos músculos tratados, que seguiram parcialmente as recomendações da literatura.

Palavras-chave: Transtornos cerebrovasculares; espasticidade muscular; toxinas botulínicas tipo A; reabilitação; metas.

Stroke is the leading cause of disability and of death in Brazil ${ }^{1,2}$. Patients usually develop motor impairments, characterized by weakness, spasticity, incoordination and limitations in active control of movements. Muscular

\footnotetext{
${ }^{1}$ Universidade de São Paulo, Faculdade de Medicina de Ribeirão Preto, Departamento de Biomecânica, Medicina e Reabilitação do Aparelho Locomotor, Ribeirão Preto SP, Brasil.

Marcelo Riberto (iD) https://orcid.org/0000-0001-9549-8830

Correspondence: Marcelo Riberto; Centro de Reabilitação do Hospital Geral de Ribeirão Preto; Avenida Bandeirantes 3900 - Bairro Monte Alegre; $14048-900$ Ribeirão Preto SP, Brasil; E-mail: mriberto@usp.br

Support: This study was not supported by the research agencies. Undergraduate students were sponsored by USP institutional scholarships.

Conflict of interest: The senior author has been supported by Allergan and Ipsen laboratories in other studies and scientific events.

Received 25 January 2019; Received in final form 27 April 2019; Accepted 05 May 2019.
} 
hyperactivity or spasticity produce inappropriate functional mechanics in the upper limbs ${ }^{3}$, and result in limitations to daily activities. Upper-limb spasticity occurs in up to $19 \%^{4}$ to $42.6 \%{ }^{5}$ of stroke survivors. Although upper and lower limbs present with the same frequency of spasticity, it is usually more severe in the former and is associated with worse functioning profiles ${ }^{6}$. Risk factors associated with the development of spasticity one year after stroke include sensorimotor impairments that can be identified with the Fugl-Meyer Assessment Scale as early as 10 days poststroke ${ }^{7}$. Besides, the spasticity in the upper limb can further disable the weakened limb and produce a range of direct negative effects, related to interference with both active and passive arm function. Secondary complications arising from spasticity include pain, impaired movements, neglected hygiene and self-care, poor self-esteem and body image, as well as pressure ulcers ${ }^{8}$.

Botulinum toxin A (BoNT-A) temporarily inhibits the release of acetylcholine in the synaptic cleft of the endplate by cleaving the SNAP-25 proteins that are responsible for the synaptic vesicle exocytosis, resulting in muscle relaxation. The best use of BoNT-A for the treatment of spasticity recommends that the exact postural limb pattern should be identified and considered when selecting the muscles for injection $^{9}$. Although the classic upper-limb posture with adducted internally-rotated shoulder, flexed elbow, flexed wrist, and clenched fist is very common, this is not the only pattern of upper-limb spasticity that can occur. Hefter et al. determined five upper-limb postural patterns of stroke survivors attributed to muscle spasticity based on the examination of 26 stroke survivors ${ }^{10}$. This posture classification system was cross-checked with data from a multicenter observational upper-limb spasticity study ${ }^{11}$ to describe the frequency of each category and draw recommendations of muscle selection for injection.

Rehabilitation goals should always be tailored according to the individual's aims, severity of impairments and environmental and personal factors. When focal spasticity is involved, the main therapeutic recommendation is injection of BoNT-A in the most-affected muscles that are in direct relation to the movement aspired to in the rehabilitation goal. The aim of the injection can be the facilitation of the use of an orthosis, reduction of pain, reduction of the burden of care for caregivers and to improve motor control in patients with residual strength in the affected extremity ${ }^{12}$. Once established, the management of spasticity may be difficult, and the clinical picture may be varied, requiring multidisciplinary approaches to achieve better outcomes. Thus, identification and treatment of spasticity are key aspects for successful stroke rehabilitation.

The aims of this study were to describe the patterns of upper-limb posture in poststroke patients scheduled for BoNT-A treatment for the control of spasticity, and to check if the muscles that would be indicated to receive injections were those treated, according to rehabilitation goals.

\section{METHODS}

Participants were recruited among patients followed at the outpatient stroke clinic in our service. They were referred for treatment with BoNT-A therapy between June 2015 and November 2017. To be included in this study, individuals had to have been diagnosed with stroke by clinical examination and brain imaging and had to have, at least, a unilateral spastic hemiparesis. Although the previous use of drugs for spasticity was tolerated, patients should not previously have been subjected to BoNT-A, alcohol or phenol neural blocks in the affected upper limb. These patients were photographed while sitting in a standardized manner and, whenever standing was possible, they were videotaped while walking with walking aids, lower-limb orthoses or support from caregivers, to give a dynamic record of the position of the upper limb.

Photos and videos were used to support the discussion and to allow the description of spontaneous upper-limb positions. These data were organized according to Hefter's upperlimb classification ${ }^{10}$ by three separate evaluators and confirmed by consensus meetings with the senior author. The patterns were characterized as follows (Figure):

1) Pattern I: internal rotation and adduction of the shoulder, flexion at the elbow, supination in the forearm, and flexion at the wrist resulting in the arm being fixed in a posture across the chest.

2) Pattern II: internal rotation and adduction of the shoulder, flexion at the elbow, supination in the forearm, and extension at the wrist.

3) Pattern III: internal rotation and adduction of the shoulder and flexion at the elbow coupled with a neutral positioning of the forearm and the wrist. The neutral position of the wrist potentially results from simultaneous contracture of the flexor and extensor muscles.

4) Pattern IV: internal rotation and adduction of the shoulder, flexion at the elbow, pronation in the forearm, and flexion at the wrist. Some variation in the degree of elbow flexion may occur.

5) Pattern V: internal rotation and retroversion of the shoulder, extension at the elbow, pronation of the forearm, and flexion at the wrist resulting in the arm being fixed in a position behind the body. This pattern of spasticity was frequently observed in connection with a dystonic component ${ }^{10}$.

Participants who could remain seated with light support from their caregivers were photographed in this position and the camera was one meter away and leveled at their manubrium. If sitting was not possible, they were photographed when supine and the researcher placed the camera perpendicular to the bed and used the same parameters. Those participants who could walk were videotaped during this task, with the help of their caregiver or canes, to check for modification of the upper-limb position during activities. The spasticity level followed the modified Ashworth scale recording of each upper-limb muscle group (shoulder adductors, elbow 


$\begin{aligned} & \text { Hefter's } \\ & \text { classification }\end{aligned}$
$\begin{aligned} & \text { Observed } \\ & \text { frequency }\end{aligned}$

Figure. Frequency of each of Hefter's classifications of spastic upper limb positions (middle row expresses the postures and lower row shows examples in the sample).

flexors and extensors, forearm pronators and supinators, wrist flexors and extensors, finger flexors).

The medical team at the rehabilitation center based their muscle therapeutic decisions on discussion with the patients and their families, taking into consideration their rehabilitation goals and an independently performed physical examination. Only after the injections were administered, could the research team retrieve information on rehabilitation goals and muscles that were treated with BoNT-A from medical records.

For statistical analysis, qualitative variables were described by the frequencies of each category while the quantitative variables were analyzed for normality by the Kolmogorov-Smirnov test and described with adequate measures of central tendency and dispersion. For each Hefter's posture, the level of spasticity measured by the modified Ashworth scale in each muscle group was expressed by median values as well as the most frequently injected muscles.

The Institutional Review Board at the Hospital das Clínicas de Ribeirão Preto approved the study and all the patients signed an informed consent. If they could not sign or understand the study, their relatives in charge signed in their place.

\section{RESULTS}

Fifty consecutive patients were included in the study, 24 (48\%) were men, and 26 (52\%) had right side spastic hemiparesis, most were in their sixth decade of life (mean age: $59.2 \pm 11.7$ years), the mean period since the stroke was $5.5 \pm 4.5$ years, and $42(84 \%)$ patients had experienced poststroke upper-limb spasticity for more than 12 months. One patient had bilateral spastic paresis, thus 51 upper limbs were counted.
The authors could properly classify all the patients according to Hefter's ${ }^{10}$ description of upper-limb posture through their pictures and videos. In the first round of independent classifications, the agreement between the evaluators occurred in $67 \%$ of the cases, but consensus could have been achieved in $100 \%$ - for example, the patient depicted in the Figure in category III with internal shoulder rotation presented with shoulder abduction, which is not described in any of Hefter's categories (Figure). Pattern I and II were noticed in only one patient each $(\sim 2 \%)$. As expected, pattern III was the most frequent (64.7\%), although shoulder rotation defined two distinctive subcategories with important reflections on the treatment: internal rotation and external rotation. We emphasize this distinction because it effectively interfered with the choice of muscles in which to inject BoNT-A. All five upper-limb patterns could be combined with any spastic hand and finger position, but this was not the aim of this paper.

The muscles most frequently treated with BoNT-A were organized by joint:

1) Shoulder: pectoralis major, latissimus dorsi and subscapularis;

2) Elbow: Biceps brachialis and triceps brachialis;

3) Forearm: pronator teres, flexor ulnaris carpi and flexor radialis carpi, flexor digitorum superficialis and flexor digitorum profundus;

4) Hand: adductor pollicis.

\section{Relationship between affected muscle and patterns}

The Table correlates the posture pattern with the frequency of muscle groups that were treated. Shadowed cells indicate the expected spastic muscle groups responsible for the upper-limb postures, so a frequent selection of those muscle groups would be expected. In the only participant who 
was classified as posture type I, the spastic muscle groups injected with BoNT-A were shoulder adductors, elbow flexors, forearm supinators and wrist flexors, which reflected the expected recommendations. Conversely, for upper-limb postures II and III, correlation was noticed only in proximal muscle groups, but not for control of supination or wrist extension in type II. Neutral forearm and wrist positions may result from simultaneous spasticity of antagonistic muscle groups in posture III, but only pronators and wrist flexors were injected. For posture type IV, most frequently pronators and elbow flexors were selected for injection, but finger and thumb flexors were preferred over wrist flexors. Finally, for posture type V, some selection of shoulder adductors was observed. Elbow control demanded triceps injection much more frequently. In all posture types, finger and thumb flexors were preferred over wrist flexors to control wrist and finger position simultaneously.

\section{DISCUSSION}

Despite the assumed usefulness of Hefter's classification system, agreement between the three evaluators was found in the first round in only $67 \%$ of the patients, which limits its use in daily routine. Although the method fixed a standard position for the collection of images, some patients could not be appropriately photographed due to unstable trunk balance, which could not guarantee the sitting position. In these patients, the images were collected in the supine position. In other situations, the patient's understanding of the commands did not allow the static position, which also compromised the standardization of image collection. Another factor that brought some confusion in the classification is that some patients presented with the elbow in extension at rest or sitting, but when walking they assumed a flexed posture. Videotapes and pictures provided stable conditions for all the evaluators; however, only after group discussion could a third of the sample be properly classified. Only with the consensus discussion was it possible to reach a definitive classification of all the postural patterns. Variables like, pain, fever, psychological distress, weather and movement may modulate the intensity of spasticity and compromise reliability of Hefter's classification in a real life clinical context.

The attitudes assumed by the body segments depend on the forces around the joints. The pyramidal syndrome initially imposes muscle weakness, compromising contraction and leads to a flaccid tone. In the upper limb, the consequence on the posture is mainly the maintenance of the limb next to the side of the body, which, if not sustained, does not assume the desired pendulum movement during gait. Patients were instructed to keep their forearms resting on their lap or armrests to prevent shoulder subdislocation, although the medical literature fails to associate shoulder pain with glenohumeral dislocation. It is still common to see stroke survivors with flaccid or spastic shoulders using slings to prevent capsular distension and reduce pain. When this motor manifestation persists for months, it is easy to observe atrophy of the deltoid muscle and the prominence of the acromioclavicular arch and humeral head, which, in the healthy person, correspond to signs of dislocation. Radiologically, sagging may be manifested by signs of glenohumeral subdislocation. In this condition, there may be local pain induced by the traction of musculoskeletal structures by the action of gravity. Not surprisingly, the position of an arm in a sling is very much the same as that of shoulder and elbow of patterns I to IV.

Spasticity is the second component of the pyramidal syndrome that can influence the determination of upper-limb posture in the hemiplegic individual ${ }^{13}$. If spasticity equally distributes through the limb muscles, then the position of the joint will be determined by the power produced by each muscle group. In the shoulder, the adductor muscles are expected to be more powerful than the abductors, while at the elbow and at the wrist, the flexors are stronger than the extensors ${ }^{14}$. This relationship of forces to the flexors and extensors of the

Table. Comparison between the frequency of muscle groups treated and recommendations in each postural pattern (shadowed cells).

\begin{tabular}{|c|c|c|c|c|c|c|c|c|c|c|c|c|}
\hline \multirow{3}{*}{ Category (n) } & \multirow{2}{*}{\multicolumn{2}{|c|}{ I (1) }} & \multirow{2}{*}{\multicolumn{2}{|c|}{ II (1) }} & \multicolumn{4}{|c|}{ III (33) } & \multirow{2}{*}{\multicolumn{2}{|c|}{ IV (11) }} & \multirow{2}{*}{\multicolumn{2}{|c|}{$\mathrm{V}(5)$}} \\
\hline & & & & & \multicolumn{2}{|c|}{ Internal (25) } & \multicolumn{2}{|c|}{ Neutral (8) } & & & & \\
\hline & Rec & Obs & $\operatorname{Rec}$ & Obs & $\operatorname{Rec}$ & Obs & $\operatorname{Rec}$ & Obs & Rec & Obs & $\operatorname{Rec}$ & Obs \\
\hline \multicolumn{13}{|l|}{ Muscles } \\
\hline Shoulder adductors & & $100 \%$ & & $100 \%$ & & $60.0 \%$ & & $50.0 \%$ & & $27.3 \%$ & & $40.0 \%$ \\
\hline Elbow flexors & & $100 \%$ & & $100 \%$ & & $64.3 \%$ & & $87.5 \%$ & & $45.5 \%$ & & $20.0 \%$ \\
\hline Elbow extensors & & $0 \%$ & & $0 \%$ & & $28.0 \%$ & & $25.0 \%$ & & $18.2 \%$ & & $40.0 \%$ \\
\hline Pronators & & $0 \%$ & & $0 \%$ & & $60.0 \%$ & & $75.0 \%$ & & $45.5 \%$ & & $0 \%$ \\
\hline Supinators & & $100 \%$ & & $0 \%$ & & $0 \%$ & & $0 \%$ & & $0 \%$ & & $0 \%$ \\
\hline Wrist flexors & & $100 \%$ & & $0 \%$ & & $20.0 \%$ & & $37.5 \%$ & & $0 \%$ & & $0 \%$ \\
\hline Wrist extensors & & $0 \%$ & & $0 \%$ & & $0 \%$ & & $0 \%$ & & $0 \%$ & & $0 \%$ \\
\hline Finger flexors & & $100 \%$ & & $100 \%$ & & $72.0 \%$ & & $87.5 \%$ & & $63.6 \%$ & & $80.0 \%$ \\
\hline Flexor pollicis longus & & $0 \%$ & & $100 \%$ & & $28.0 \%$ & & $37.5 \%$ & & $36.4 \%$ & & $20.0 \%$ \\
\hline Adductor pollicis & & $0 \%$ & & $0 \%$ & & $24.0 \%$ & & $0 \%$ & & $9.1 \%$ & & $0 \%$ \\
\hline
\end{tabular}


fingers is not found in literature, but intuitively it is believed to be a predominance of the former. This theoretical assumption meets the postural patterns III and IV, which accounted for $86.27 \%$ of the sample, namely with internal rotation and adduction of the shoulder and flexion and pronation at the elbow coupled with a neutral or flexed position of the wrist. Internal rotators of the shoulder share the same insertion as the adductors and are mainly the same muscles, thus it is expected that the adducted shoulder is also internally rotated. Also, muscles with flexor influence on the wrist are also active during pronation, so both attitudes are observed simultaneously. Similarly, finger and thumb flexors also produce wrist flexion, pronation and some elbow flexion, making them a very suitable target for BoNT-A injection for the control of those movements. Although this is the basis of the argument of this article, it is important to note that muscle shortening and, therefore, postures, are not substantially modified by antispasmodic medications, which control spasticity. Therefore, other mechanisms for the development of postures should be considered.

Finally, muscle attachment also defines posture: muscle shortening occurs in up to $60 \%$ of severely disabled stroke survivors $^{15}$. A joint held in the same posture for long may evolve with shortening of noncontractile components, such as collagen fibers between muscle fibers, fascias and even modification of the joint capsule. Sometimes, muscle shortening is iatrogenic in nature, when the health team promotes prolonged immobilization in the acute phase. Atrophy of muscle fibers caused by nerve damage and inactivity leads to a reduction in the diameter of the fibers and not to their length, but muscles subjected to procedures, like injections or excessive improper therapeutic manipulation, may evolve with localized collagen deposition and overall shortening. Assessment of spasticity with the modified Ashworth scale exclusively considers the velocity-dependent resistance to passive movement, but this can result from muscle spasticity and from fascial and capsular contraction. The Tardieu scale is the only test that differentiates these components of muscle resistance to passive movement, but it may be quite time consuming and less useful in a clinical context.

Each of the components described above helps the understanding of the genesis of muscle contractions and the positions assumed by body segments. Different pathways can be studied in the pathophysiological mechanism of muscle contraction resulting from lesions of the nervous system, depending on the patient, the disease, the location of the injury, and local and general preventive health care conditions. Recently, Pingel et al. ${ }^{16}$ proposed a multidimensional model related to homeostasis in the tissue complex involving the connective tissue, tendon and neuromuscular component in which these tissues interact with different stimuli, such as neural activity, nutrition, mechanical and genetic factors, leading to adaptive changes of the system. In the lower limb, the concept of spasticity of the antigravitational muscles makes sense, as these muscle groups are the most bulky and potent of the lower limb. On the other hand, in the upper limb, the determination of posture seems to be more related to the way it is kept throughout the day than to the neurological lesion itself. Alternatively, Sheean's neurophysiological model suggests a topographic correlation with the descending pathways involved in the central nervous system injury ${ }^{17}$.

One of the strong aspects of this study is that the choice of muscles for the treatment with BoNT-A was made by doctors who examined the patients and defined rehabilitation goals with them and their caregivers, independently from the research team. Thus, muscle selection was not biased by the study, and the results strongly reproduced regular clinical practices. An exhaustive anatomical and biomechanical study of each muscle action is required to best select muscles to be injected and to control spastic movements. However, we could not find studies that compared similar muscle choices. Thus, although the biceps brachii is not the most powerful flexor of the elbow and has some supination activity, it has not been clinically proven that equal doses of BoNT-A injected in the brachialis, which does not produce any pronation, would have any clinical difference in spasticity treatment in a patient with a pronated forearm, as in postures IV and V. This may be the reason some services have different experiences in muscle choice, approach and dosing for BoNT-A injection, and may explain the diverse muscle selection.

This study was based on the experience of only one rehabilitation center, thus it expresses the therapeutic principles of that service, which may be considered a decision bias, and may limit the generalizability and external validation of the study. We believe, though, that rehabilitation goals are somewhat widespread among university rehabilitation centers in Brazil and this is an issue that is frequently discussed in scientific meetings among rehabilitation professionals. Also, another limitation of this study is that some patients also needed part of the total dose of BoNT-A reserved for lower limbs and this influenced the dose for the upper limbs and muscle selection.

We were able to properly classify upper-limb spastic posture of stroke survivors in $67 \%$ of the cases. The most frequent posture included shoulder adduction, elbow flexion and neutral position of the wrist in $64.7 \%$ of the patients. Some suggestions on muscle selection based on our results are: shoulder adductors and elbow flexors should always be investigated for spasticity, no matter which posture pattern is considered. Elbow extensors should be injected in posture type $\mathrm{V}$, but can also be investigated and treated when this joint is rigid or painful on passive mobilization. Forearm and wrist positions cannot fully predict muscle selection. In our service, finger and thumb flexors were selected in more than $63 \%$ of the patients to control passive resistance of this segment. A recent review on muscle choice for BoNT-A treatment in the spastic upper limb after a stroke may be used as 
a guide for the inexperienced physician ${ }^{9}$, and we add some advice on muscle choice in the distal part of the upper limb, namely in the fingers and thumb. However, we emphasize that the goal of rehabilitation treatment may not be the restoration of normal tone, but rather functioning, comfort and safety. Thus, in a chronic spastic upper limb, which fails to recover strength after adequate therapeutic stimulation, the therapeutic functional goal may be proper positioning at rest, comfortable use of an orthosis, prevention of deformities, and maintenance of hygiene or pain control. The sole classification according to Hefter's patterns or the evidence of spasticity on physical examination is not enough to define muscle as a target for BoNT-A treatment. The definition of treatment should also consider the patient's and caregiver's expectations and aims, as well as the experience of the multidisciplinary rehabilitation team.

\section{References}

1. American Heart Association. Heart disease and stroke statistics - 2017 update: a report from the American Heart Association. Circulation. 2017 Mar;135(10):e146-603. https://doi.org/10.1161/CIR.0000000000000485.

2. Cabral NL. Gonçalves AR, Longo Al, Moro CH, Amaral CH, Souza $\mathrm{MV}$, et al. Trends in stroke incidence, mortality and case fatality in Joinville, Brazil: 1995-2006. J Neurol Neurosurg Psychiatry. 2009;80(7):749-54. https://doi.org/10.1136/jnnp.2008.164475

3. Kalichman L, Ratmansky M. Underlying pathology and associated factors of hemiplegic shoulder pain. Am J Phys Med Rehabil. 2011 Sep;90(9):768-80. https://doi.org/10.1097/PHM.0b013e318214e976

4. Sommerfeld DK, Eek EU, Svensson AK, Holmqvist LW, von Arbin MH. Spasticity after stroke: its occurrence and association with motor impairments and activity limitations. Stroke. 2004 Jan;35(1):134-9. https://doi.org/10.1161/01.STR.0000105386.05173.5E

5. Urban PP, Wolf T, Uebele M, Marx JJ, Vogt T, Stoeter $P$, et al. Occurence and clinical predictors of spasticity after ischemic stroke. Stroke. 2010 Sep;41(9):2016-20. https://doi.org/10.1161/STROKEAHA.110.581991

6. Watkins CL, Leathley MJ, Gregson JM, Moore AP, Smith TL, Sharma AK. Prevalence of spasticity post stroke. Clin Rehabil. 2002 Aug;16(5):515-22. https://doi.org/10.1191/0269215502cr512oa

7. Opheim A, Danielsson A, Alt Murphy M, Persson HC, Sunnerhagen KS. Early prediction of long-term upper limb spasticity after stroke: part of the SALGOT study. Neurology. 2015 Sep;85(10):873-80. https://doi.org/10.1212/WNL.0000000000001908

8. Fheodoroff K, Ashford S, Jacinto J, Maisonobe P, Balcaitiene J, Turner-Stokes L. Factors influencing goal attainment in patients with post-stroke upper limb spasticity following treatment with botulinum toxin A in real-life clinical practice: sub-analyses from the Upper Limb International Spasticity (ULIS)-II Study. Toxins (Basel). 2015 Apr;7(4):1192-205. https://doi.org/10.3390/toxins7041192

9. Simpson DM, Patel AT, Alfaro A, Ayyoub Z, Charles D, Dashtipour $\mathrm{K}$, et al. Onabotulinumtoxin A injection for poststroke upper-limb spasticity: guidance for early injectors from a Delphi panel process. PM R. 2017;9(2):136-48.
10. Hefter H, Jost WH, Reissig A, Zakine B, Bakheit AM, Wissel J. Classification of posture in poststroke upper limb spasticity: a potential decision tool for botulinum toxin A treatment? Int J Rehabil Res. 2012 Sep;35(3):227-33. https://doi.org/10.1097/MRR.0b013e328353e3d4

11. Bakheit AM, Zakine B, Maisonobe P, Aymard C, Fhedoroff K, Hefter $\mathrm{H}$, et al. The profile of patients and current practice of treatment of upper limb muscle spasticity with botulinum toxin type A: an international survey. Int J Rehabil Res. 2010 Sep;33(3):199-204. https://doi.org/10.1097/MRR.0b013e328332f5e0

12. Foley N, Pereira S, Salter K, Fernandez MM, Speechley M, Sequeira K, et al. Treatment with botulinum toxin improves upper-extremity function post stroke: a systematic review and meta-analysis. Arch Phys Med Rehabil. 2013 May;94(5):977-89. https://doi.org/10.1016/j.apmr.2012.12.006 PMID:23262381

13. Gracies JM. Coefficients of impairment in deforming spastic paresis. Ann Phys Rehabil Med. 2015 Jun;58(3):173-8. https://doi.org/10.1016/j.rehab.2015.04.004

14. Harbo T, Brincks J, Andersen H. Maximal isokinetic and isometric muscle strength of major muscle groups related to age, body mass, height, and sex in 178 healthy subjects. Eur J Appl Physiol. 2012 Jan;112(1):267-75. https://doi.org/10.1007/s00421-011-1975-3

15. Sackley C, Brittle N, Patel S, Ellins J, Scott M, Wright C, et al. The prevalence of joint contractures, pressure sores, painful shoulder, other pain, falls, and depression in the year after a severely disabling stroke. Stroke. 2008 Dec;39(12):3329-34. https://doi.org/10.1161/STROKEAHA.108.518563

16. Pingel J, Bartels EM, Nielsen JB. New perspectives on the development of muscle contractures following central motor lesions. J Physiol. 2017 Feb;595(4):1027-38. https://doi.org/10.1113/JP272767

17. Sheean G. The pathophysiology of spasticity. Eur J Neurol. 2002 May;9(s1 Suppl 1):3-9. https://doi.org/10.1046/j.1468-1331.2002.0090s1003.x 